\title{
Electromagnetic Forming Process Analysis Based on Coupled Simulations of Electromagnetic Analysis and Structural Analysis
}

\author{
Man Gi Lee', Seung Hwan Lee², Sunwoo Kim³ , and Jin Ho Kim ${ }^{4 *}$ \\ ${ }^{1,4}$ Department of Mechanical Engineering, Yeungnam University, Gyeongsan, Gyeongbuk 38541, Republic of Korea \\ ${ }^{2}$ School of Aerospace and Mechanical Engineering, Korea Aerospace University, Goyangsi, Gyeonggido 10540, Republic of Korea \\ ${ }^{3}$ Department of Mechanical Engineering, University of Alaska Fairbanks, Alaska, USA
}

(Received 29 February 2016, Received in final form 9 April 2016, Accepted 11 April 2016)

\begin{abstract}
We conducted a phased electromagnetic forming process analysis (EFPA) over time through a coupling of electromagnetic analysis and structural analysis. The analysis is conducted through a direct linkage between electromagnetic analysis and structural analysis. The analysis process is repeated until the electric current is completely discharged by a formed coil. We calculate the forming force that affects the workpiece using MAXWELL, a commercial electromagnetic finite element analysis program. Then, we simulate plastic behavior by using the calculated forming force data as the forming force input to ANSYS, a commercial structure finite element analysis program. We calculate the forming force data by using the model shape in MAXWELL, a commercial electromagnetic finite element analysis program. We repeat the process until the current is fully discharged by the formed coil. Our results can be used to reduce the error in data transformation with a reduced number of data transformations, because the proposed approach directly links the electromagnetic analysis and the structural analysis after removing the step of the numerical analysis of a graph describing the forming force, unlike the existing electromagnetic forming process. Second, it is possible to simulate a more realistic forming force by keeping a certain distance between nodes using the re-mesh function during the repeated analysis until the current is completely discharged by the formed coil, based on the MAXWELL results. We compare and review the results of the EFPA using the peak value of the forming force that acts on the workpiece (which is the existing analysis method), and the proposed phased EFPA over time approach.
\end{abstract}

Keywords : coupled analysis, electromagnetic forming process analysis (EFPA), MAXWELL, ANSYS

\section{Introduction}

An electromagnetic forming device is used to form a workpiece and circular tube using high strength magnetic energy. The device forms the workpiece after current is discharged by the formed coil; induced electromotive force is created in the workpiece by the discharged current in the formed coil; and a Lorentz force is generated using the induced electromotive force. For 20 years, many studies have been conducted that simulate this plasticity process. In 1997, B. K. et al. conducted an analysis on the state of location of a solenoid coil within metal cylinders used to expand the cylinders, after resetting the mesh depending on each step time [1]. In 1999, Azzouz et al.

CThe Korean Magnetics Society. All rights reserved.

*Corresponding author: Tel: +82-53-810-2441

Fax: +82-53-810-4627, e-mail: jinho@ynu.ac.kr
Electronique used a two-dimensional (2-D) axial symmetry finite element model to analyze circular tubes. They reduced the analysis time by differentiating the size of mesh of the coil part and forming material part, and expanding the mesh size of the unnecessary parts to be analyzed. In addition, they improved accuracy by controlling the size of mesh of the parts that are required to be accurate [2]. In 2005, Yu et al. conducted an analysis using circular tubes and the ANSYS commercial analysis program. They generated a larger forming force by reducing the size of the field that applied the forming force using a field shaper [3]. In 2008, J. et al. conducted examined an electromagnetic forming device that forms the workpiece, and studied the molded depth of the formed coil over time using a simple model of a single turn [4]. In 2009, Y. U. et al. used a 2-D axially symmetric finite element model to analyze circular tubes. They set the mesh size of the inside of the tubes and the 
coil parts differently, expanded the size of the mesh in the unnecessary parts, and reduced the size of the mesh in the formed coil. Their analysis result identified the molded depth over time [5]. In 2009, Liu et al. improved the accuracy of mold dies and shapes using a formed coil in the unprocessed smallest part due to the spring back of a formed aluminum workpiece [6]. In 2010, Lee et al. verified the molded depth of working pieces according to the applied voltage passing through an electromagnetic forming device test [7]. In 2011, V. et al. conducted a test with an electromagnetic forming device in order to identify the relationship between molded depth and forming time, and considered the use of different formed coils, depending on the shape of the workpiece, as a forming device to form slots in the workpiece in order to reduce or expand tubes [8]. In 2012, J. et al. conducted research to form a workpiece and carry out a second formation in the same shape as the mold dies using the formed coil in the unprocessed parts of the slot or corner areas [9]. In the same year, Shim et al. conducted a research on the coil of an electromagnetic forming device using three types of coils: bar, pancake, helical [10]. In addition, in March, 2013, Noh et al. conducted a finite element analysis using the Garson plasticity model to determine why electromagnetic forming technology has improved compatibility compared to other methods. They confirmed that the workpiece generates the stress constant outside the workpiece through the impact of contacting mold dies, and that the forming performance increased due to the subsequent volumetric shrinkage of the gaps [11]. In July of the same year, Kim et al. also identified the impact of material manipulation on the electromagnetic field and forming force by conducting sequential electromagnetic-mechanical coupled simulations on the free bulge and electromagnetic forming of the Steel Plate Cold Comerica (SPCC) using a 2-D axisymmetric model with ANSYS EMAG software [12]. However, the research described in has the disadvantage that the forming force was more heavily acted due to the much distribution of nodes on the concentrated parts of nodes of workpiece meshes depending on the change of the workpiece, and the forming force was less acted due to the increased gap between the nodes in the areas where nodes are dispersed. Recent research by Lee et al. concerns optimized design to improve the function of a magnetic pulse forming device. They set the number of coil turns, the capacitance, and the voltage as the main design factors of a Magnetic Pulse Forming (MPF) system and conducted an optimal design to maximize the forming force. Magnetic 2-D MAXWELL transient analysis was conducted to calculate the forming force acting on the workpiece until the current was completely discharged by the formed coil of the MPF system. It converted the biggest forming force into an expression using the curve fitting function of MATLAB, and calculated the plastic behavior of the workpiece by inputting the expression as the forming force into a structural 3-D ANSYS static analysis [13]. However, this research uses the biggest forming force among the forming forces resulting from the magnetic 2-D MAXWELL transient analysis in the structural analysis after converting the forming force into an expression, and conducts the structural analysis only when the highest forming force is applied. This time, as the forming force acting on the workpiece was analyzed using only the forming force at the moment when the forming force was maximized rather than the time at which the current was completely discharged by the formed coil, there is a disadvantage not to consider forming force in the other parts excluding the maximized forming force. Therefore, this study analyzed the forming process by directly linking transient electromagnetic analysis and transient structural analysis using 3-D MAXWELL software and 3-D ANSYS software. It calculated the forming force using the magnetic 3-D MAXWELL transient analysis and analyzed the forming behavior of the workpiece given the forming force and inertial force calculated in the structural 3-D ANSYS transient analysis. The analyzed forming model is input as a forming model to the magnetic 3-D MAXWELL transient analysis program again, and a magnetic 3-D MAXWELL transient analysis is conducted again. This process is repeated until the current is fully discharged by the formed coil. In addition, this research simulated to enter the forming force acting on the workpiece more practically by reassigning mesh depending on the change of the workpiece after applying the re-mesh function of the magnetic 3-D MAXWELL transient analysis, and keeping a certain distance between nodes.

\section{Structure and Operation Principle of Electromagnetic Forming Device}

The proposed electromagnetic forming device is divided into an electrical control circuit and a forming device. The two parts are connected with wire, as shown in Fig. 1. The electrical control circuit is mainly comprised of capacitor and charging/discharging switch. On the other hand, the forming device consists of a coil, a workpiece, and a die.

The operating principle of the electromagnetic forming device can be categorized into four steps. The first step is the initial state, as shown in Fig. 2(a). In this state, the charging and switch is off and the capacitor is not charged 


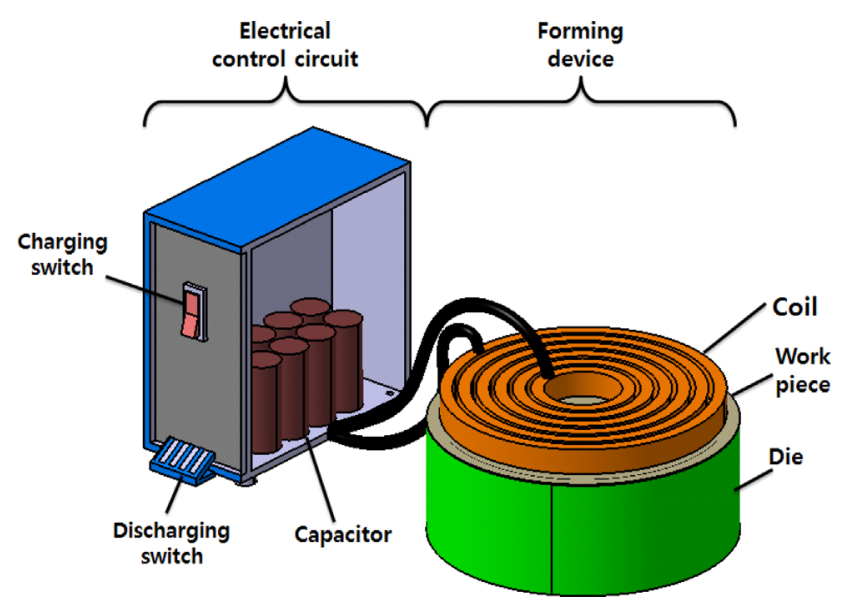

Fig. 1. (Color online) Electromagnetic forming device.

by the current. In the second step, the capacitor is charged which means that the charging switch turned on, as shown in Fig. 2(b). The third step is a process in which

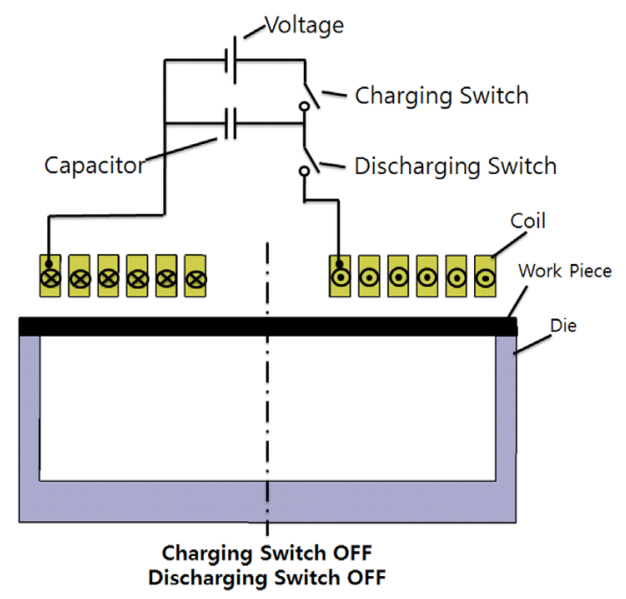

(a) Initial state before forming

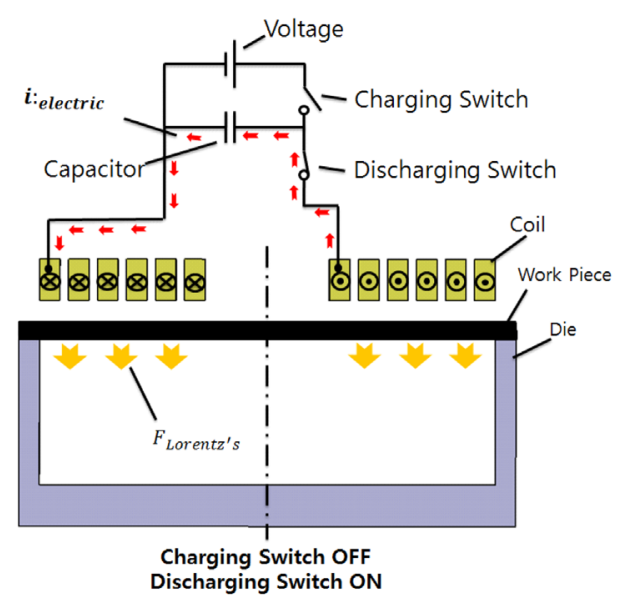

(c) Capacitor discharge the current in the capacitor is discharged, as shown in Fig. 2(c). The current in the formed coil is being discharged. At this stage, the plastic deformation begins by the Lorentz force. The fourth step is the main forming process, as shown in Fig. 2(d). In this step, the forming process ends [13].

\section{Process of Coupled Analysis}

3.1. Electromagnetic forming process analysis using peak value of forming force acting on the workpiece

Figure 3(a) shows the schematic of the analysis steps for the existing simulation study and Fig. 3(b) shows the improved step which considers the transient current respectively.

For precise analysis on forming process, the Lorentz force induced by time-varying current, the magnetic analysis is required, as an input for mechanical analysis. The electromagnetic analysis is analyzed by MAWELL.

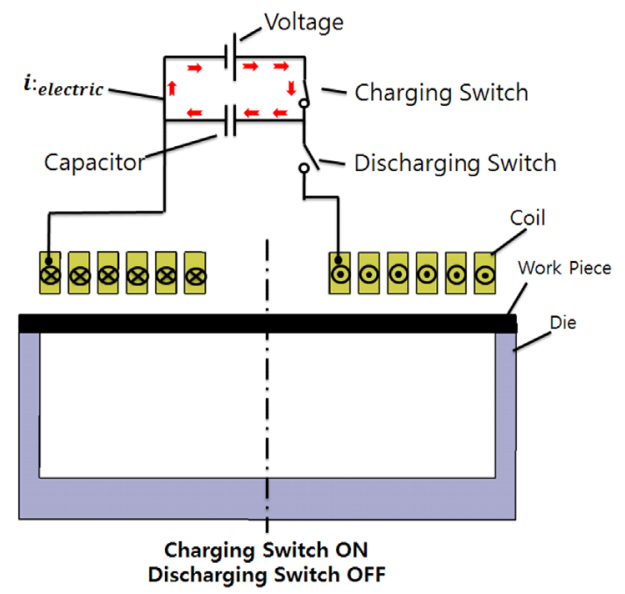

(b) Charging capacitor

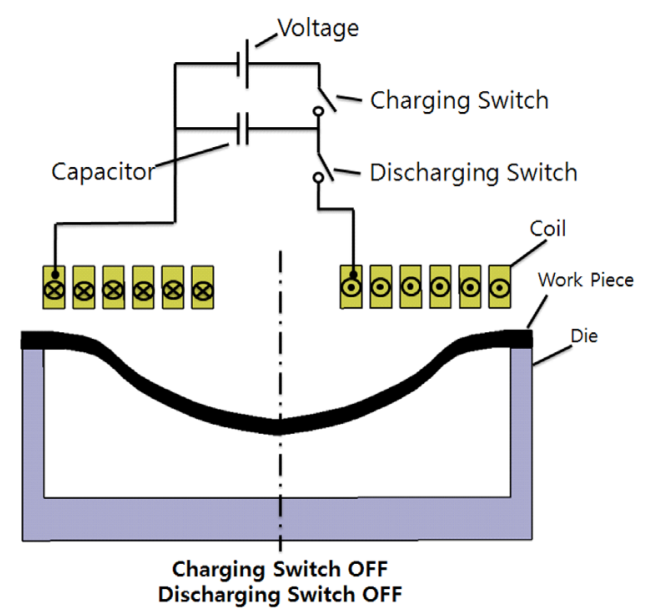

(d) After forming

Fig. 2. (Color online) Operating order of electromagnetic forming device. 


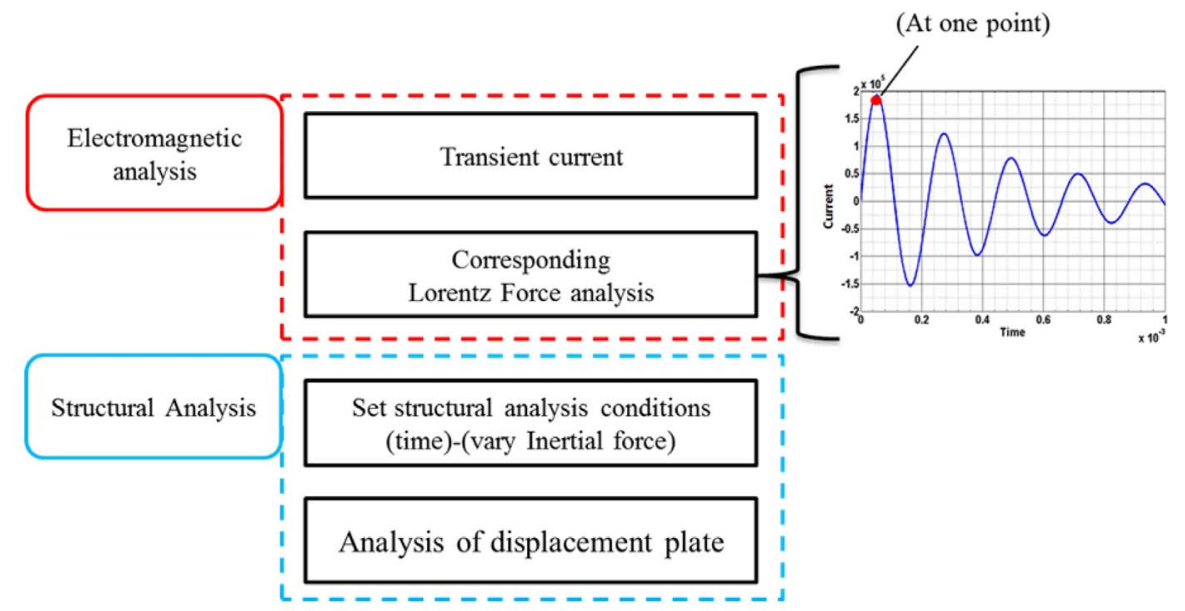

(a) The existing simulation

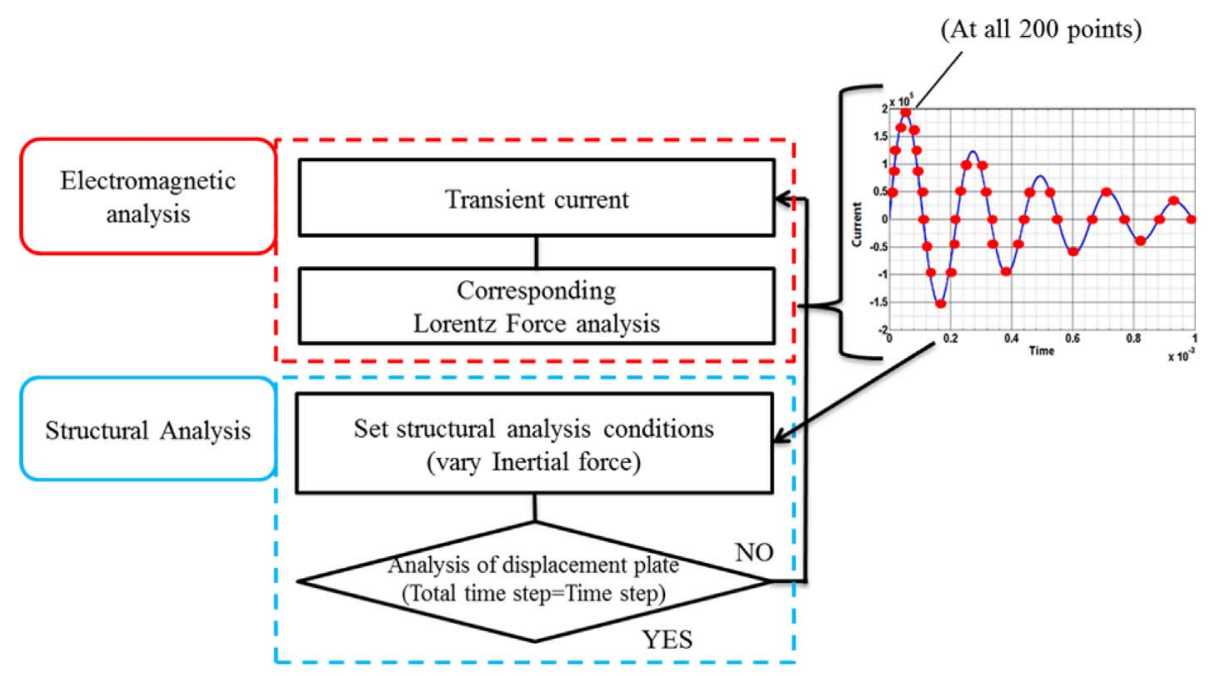

(b) The simulation considering the transient current

Fig. 3. (Color online) Schematic diagram of electromagnetic Forming Simulation.

In this step, the highest voltage during the discharged current in the formed coil is utilized.

The shape of the workpiece was simplified using 2-D cylindrical coordinates as shown in Fig. 4. Here, the coil is copper, the die is stainless steel, and the work piece is aluminum. In the Table 1, the details of the materials are summarized.

Table 1. The physical properties of the material.

\begin{tabular}{lccc}
\hline \hline & Copper & $\begin{array}{c}\text { Stainless } \\
\text { Steel }\end{array}$ & $\begin{array}{c}\text { Work } \\
\text { Piece }\end{array}$ \\
\hline Electric Conductivity $(\mathrm{mho} / \mathrm{m})$ & $580 \times 10^{5}$ & $20 \times 10^{5}$ & $380 \times 10^{5}$ \\
Relative Permeability & 0.999991 & 1 & 1.000021 \\
Young's Modulus $(\mathrm{Pa})$ & $1.1 \times 10^{11}$ & $1.93 \times 10^{11}$ & $7.1 \times 10^{10}$ \\
Poisson's ratio & 0.34 & 0.31 & 0.33 \\
Density $\left(\mathrm{kg} / \mathrm{m}^{3}\right)$ & 8300 & 7750 & 2770 \\
\hline
\end{tabular}

In Fig. 4, the applied voltage in the formed coil was input as a function over time as shown in Eq. (1). In this equation, $I_{\text {peak }}$ is the largest current, $L_{\mathrm{sys}}$ is the inductance of the system, $V_{0}$ is the input voltage, $\mathrm{E}$ is the stored

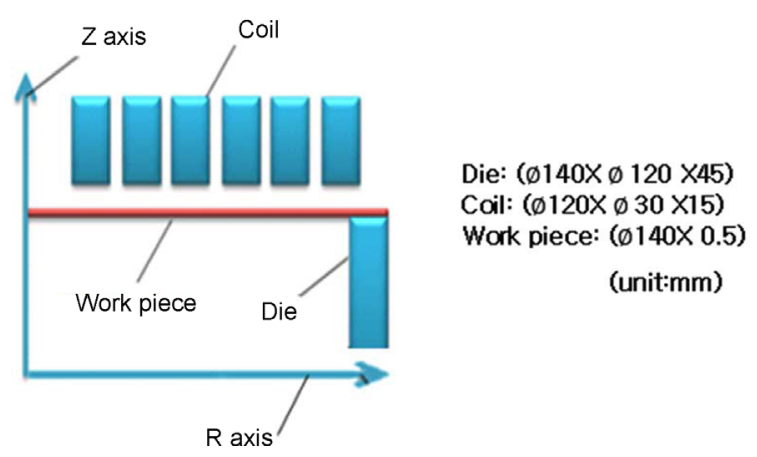

Fig. 4. (Color online) 2-D axisymmetric model for transient analysis. 
Table 2. Electrical setup conditions.

\begin{tabular}{lccc}
\hline \hline & $\begin{array}{c}\text { No. of coil } \\
\text { turns }\end{array}$ & Capacitance & Voltage \\
\hline Model specifications & 6 & $500 \mu \mathrm{F}$ & $5 \mathrm{kV}$ \\
\hline
\end{tabular}

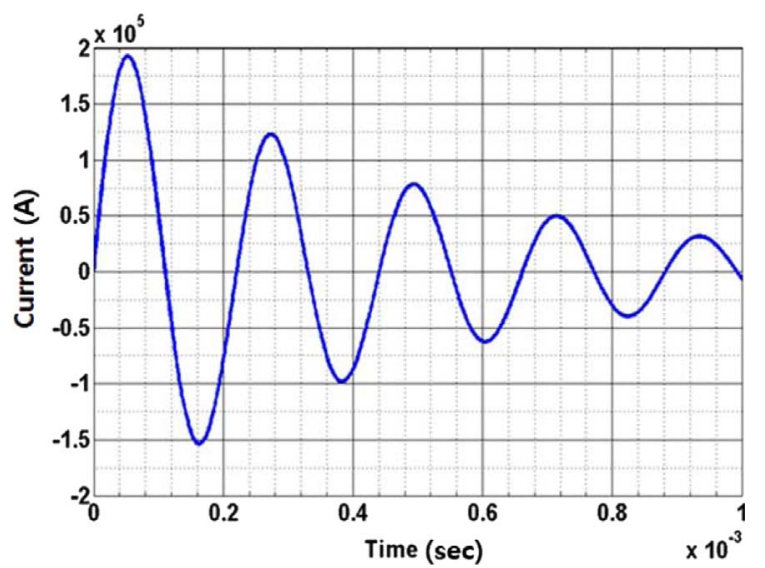

Fig. 5. (Color online) Electric current decreasing with respect to time.

energy, and $f_{1}$ is a constant with the resistance of the total system as a function.

$$
I_{\text {peak }}=f_{1} V_{0} \sqrt{\frac{c}{L_{\text {sys }}}}=f_{1} \sqrt{\frac{2 E}{L_{\text {sys }}}}
$$

The workpiece is positioned on the die. The workpiece is fixed against the $\mathrm{z}$ axis and the coil was apart from the workpiece with $2 \mathrm{~mm}$. The number of coil turns of the forming device used in the analysis, the capacitance, and voltage of the capacitor of the electrical control circuit are shown in Table 2.

The time varying current has a shape shown in Fig. 5. The total analysis time was $1 \mathrm{~ms}$ and the time step was $0.5 \mu$ s. At each time step, the Lorentz force is calculated. The time for having the maximum induced force was checked because of the calculation of the forming force which exert on the workpiece at that time. As shown in Fig. 6, the exerted force to the workpiece is fitted using the $8^{\text {th }}$ order sinusoidal function to calculate the displacement of the workpiece for the structure analysis. The $\mathrm{x}$-axis is the position of plate and the $\mathrm{y}$-axis is forming pressure.

The finite element model used in the structural 3-D ANSYS analysis is shown in Fig. 7(a). After entering the formula from the fitting result of Fig. 6, the forming force was calculated with a circular shape, as shown in Fig. 7(b). For the structure analysis, the adaptive mesh is used and the total element is 20334 .

The displacement result of the workpiece by the force

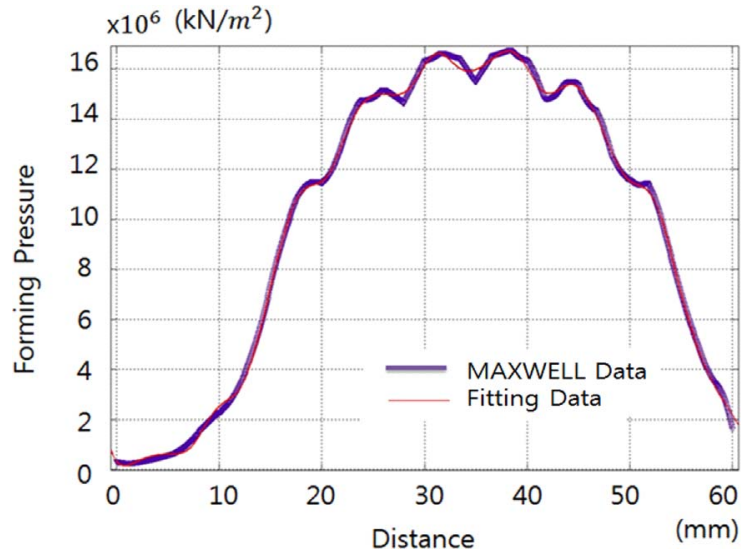

Fig. 6. (Color online) Curve fitting graph.

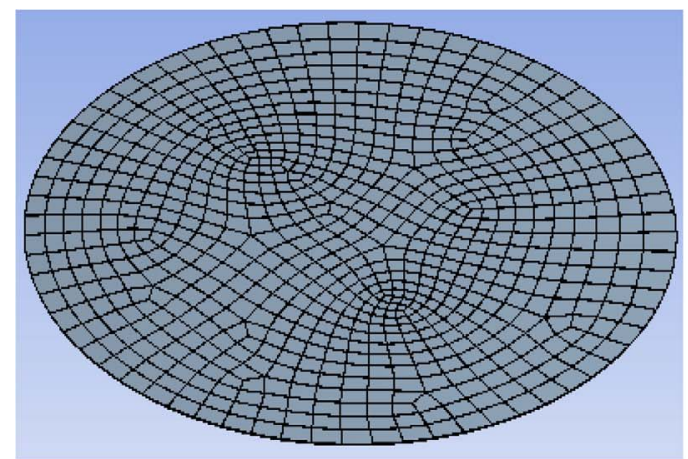

(a)

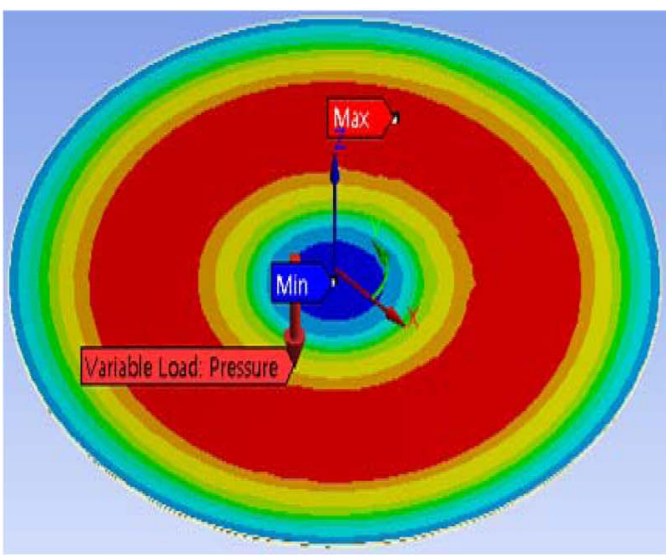

(b)

Fig. 7. (Color online) (a) 3-D finite element model. (b) Forming force acting on the workpiece in the structural analysis.

induced by the 2-D transient current is shown in Fig. 8.

\subsection{Phased electromagnetic forming process analysis}

For the magnetic 3-D transient analysis, it is required to set the approved voltage on a shape model The shape model is shown in Fig. 9. The conditions used are same with Table 2. 


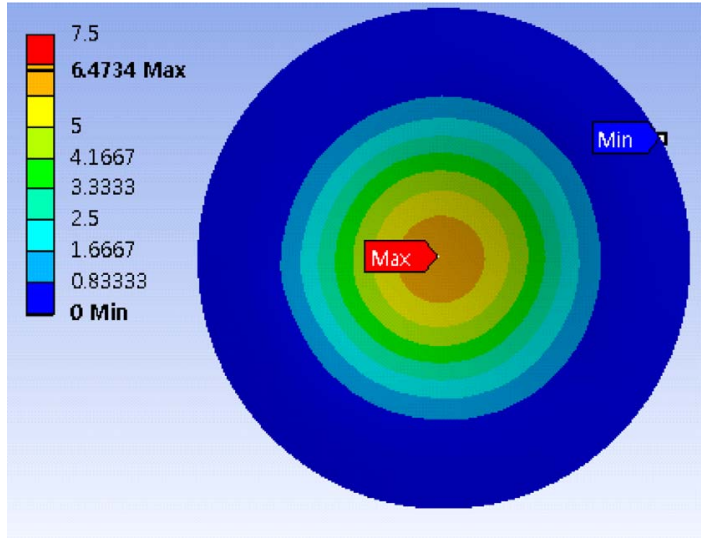

Fig. 8. (Color online) Displacement results of workpiece of existing simulation $(\mathrm{mm})$.

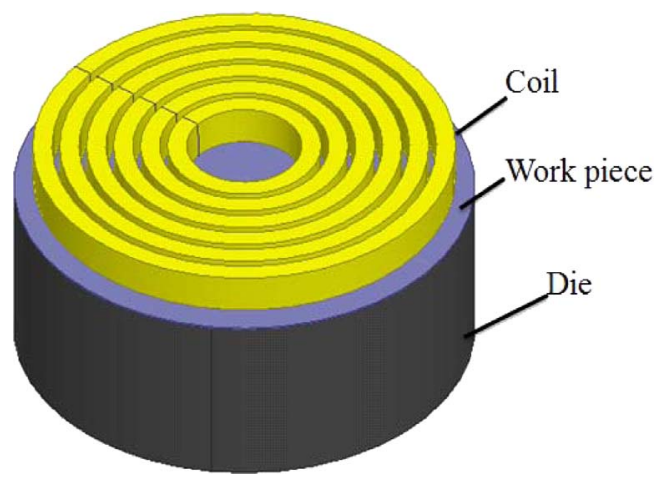

Fig. 9. (Color online) 3-D shape model of the ANSYS transient structural analysis.

The total analysis time was $1 \mathrm{~ms}$, which is the time needed until the current is fully discharged by the formed coil. The time step was $0.5 \mu \mathrm{s}$. A structural 3-D ANSYS transient mode was used to analyze the displacement of the workpiece, as the calculated inertial force was acting on the workpiece using Eq. (2). To satisfy the total analysis time, we used the analyzed workpiece shape model. We performed electromagnetic analysis by consistently maintaining the distribution between nodes of the workpiece using the re-mesh function due to the inconsistent distance between the nodes of the workpiece. The second structural analysis was conducted based on the concurrent action of the forming force calculated by the second electromagnetic analysis and the recalculated inertial force. The coupled analysis was conducted using 2001 iterations until the current was completely discharged by the formed coil.

$$
\mathrm{M} \ddot{u}(t)+C \dot{u}(t)+K u(t)=F(t)
$$

The displacement analysis results of the workpiece are shown in Fig. 10.

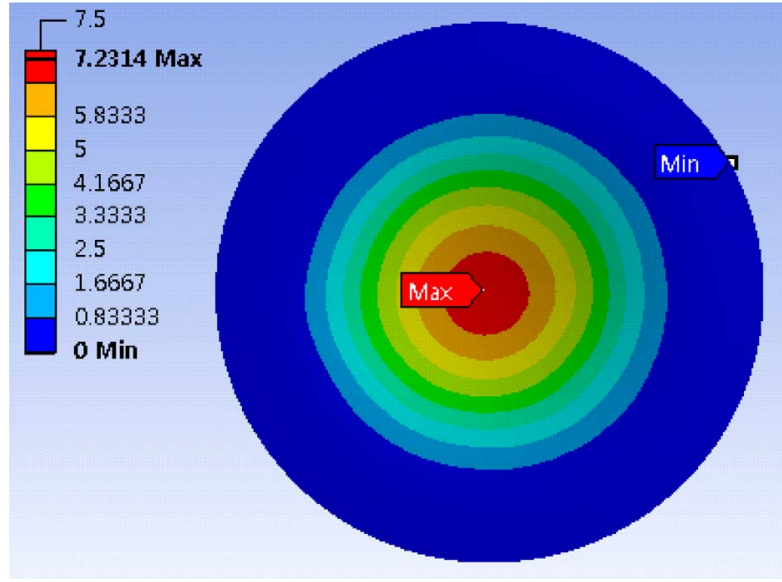

Fig. 10. (Color online) Displacement results of workpiece of simulation considering the transient current $(\mathrm{mm})$.

\section{Comparison of Analysis Results}

Table 3. Shows the results of the analysis under the same conditions of the EFPA using the peak value of the forming force acting on the workpiece and the phased EFPA over time. The maximum molded depth of the workpiece is $6.4734(\mathrm{~mm})$ in the EFPA using the peak value of the forming force acting on the workpiece, and $7.2314(\mathrm{~mm})$ in the phased EFPA over time. The molded

Table 3. Molded depth of analysis comparison.

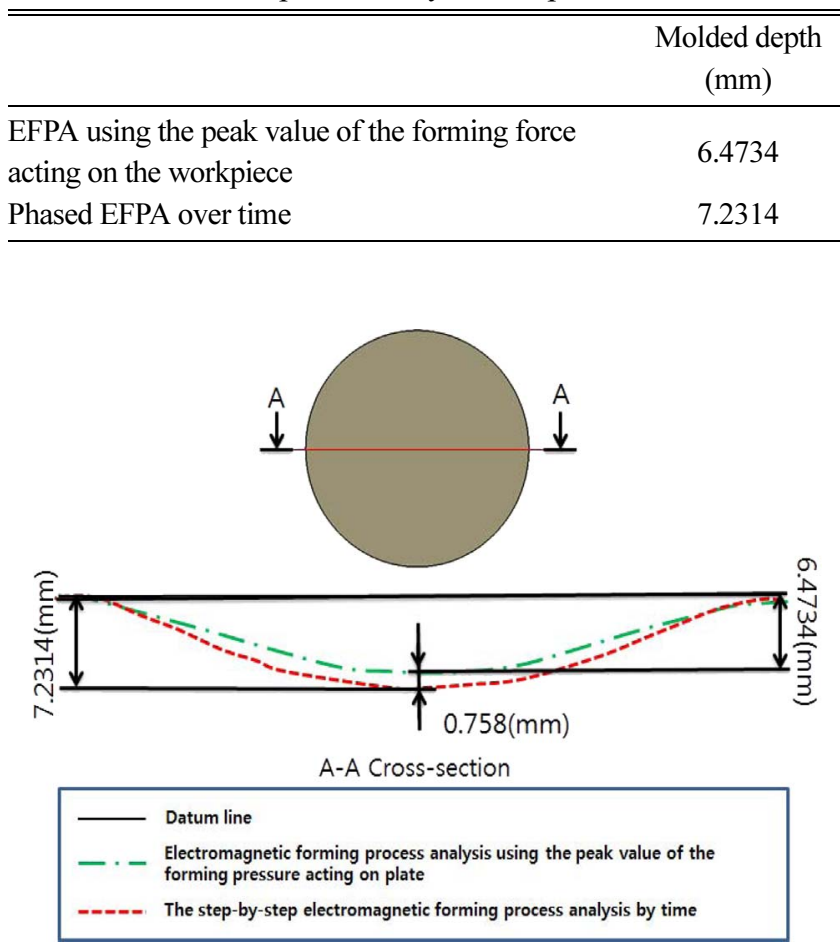

Fig. 11. (Color online) Comparison of the cross-section. 
depth increased by $11.7 \%$ in the phased EFPA over time compared to the EFPA using the peak value of the forming force acting on the workpiece.

Figure 11 compares the displacement of the workpiece between the EFPA using the peak value of the forming force acting on the workpiece and the phased EFPA over time in the cross section.

\section{Conclusion}

We propose a phased electromagnetic forming process analysis (EFPA) over time to analyze an electromagnetic forming device, and examined the peak value of the forming force acting on the existing workpiece and the phased EFPA over time under the same conditions. The molded depth was $6.4734 \mathrm{~mm}$ in the EFPA using the peak value of the forming force acting on the workpiece and $7.2314 \mathrm{~mm}$ in the phased EFPA over time. The two analysis results were demonstrated in cross-section, and both analyses had different molded depths because of the different analysis processes. The EFPA using the peak value of the forming force acting on the workpiece was conducted with structural 3-D ANSYS static analysis only using the peak value of the forming force data that is discharged by the workpiece. The phased EFPA over time conducted the coupled analysis by coupling the magnetic 3-D MAXWELL transient analysis and structural 3-D ANSYS transient analysis after considering both the forming force acting until the current is fully discharged by the formed coil, and the calculated inertial force due to the forming acceleration and mass of the workpiece. The molded depth of the workpiece increased by $11.7 \%$ in the phased EFPA over time compared to the EFPA using the peak value of the forming force acting on the workpiece.

\section{References}

[1] B. Bendjima, K. Srairi, and M. Feliachi, IEEE Trans. Magn. 33, 1638 (1997).

[2] F. Azzouz, B. Bendjima, M. Féliachi, and M. E. Latreche, IEEE Trans. Magn. 35, 1845 (1999).

[3] H. Yu, C. Li, Z. Zhao, and Z. Li, J. Mater. Proc. Technol. 168, 245 (2005).

[4] J. Unger, M. Stiemer, M. Schwarze, B. Svendsen, H. Blum, and S. Reese, J. Mater. Proc. Technol. 199, 341 (2008).

[5] Y. U. Haiping, L. I. Chunfeng, and D. E. N. G. Jianghua, J. Mater. Proc. Technol. 209, 707 (2009).

[6] D.-H. Liu, C.-F. Li, and Y. Hai-Ping, Trans. Nonferrous Metals Society of China 19, 1294 (2009).

[7] H. M. Lee, B. S. Kang, and J. Kim, Trans. Mater. Proc. 19, 1 (2010).

[8] V. Psyk, D. Risch, B. L. Kinsey, A. E. Tekkaya, and M. Kleiner, J. Mater. Proc. Technol. 211, 787 (2011).

[9] J. Imbert and M. Worswick, J. Mater. Proc. Technol. 212, 1963 (2012).

[10] J. Y. Shim, B. Y. Kang, and I. J. Kim, KSMTE 322 (2012).

[11] H. G. Noh, W. J. Somg, B. S. Kang, and J. Kim, Kor. Soc. Mech. Eng. 13, 240 (2013).

[12] J. Kim, H. G. Noh, S. J. Ko, and T. J. Kim, Trans. Mater. Proc. 21, 441 (2012).

[13] M. G. Lee, S. H. Lee, B. H. Park, and J. H. Kim, J. Vibroengineering Issue 7 (2015). 